\title{
Nutritional knowledge of youth academy athletes
}

Stephen P. Bird ${ }^{1,2^{*}}$ and Benjamin D. Rushton ${ }^{3}$

\begin{abstract}
Background: Youth athletes are under increasing pressures to excel in their chosen sport and many turn to nutritional supplements in order to enhance sports performance. However, athletes may obtain their nutritional information via illegitimate sources such as the internet, media, and other athletes, representing miscommunication between sound scientific information and anecdotal experiences. The objective of this investigation was to examine nutrition knowledge of elite youth athletes from a non-residential regional academy of sport.

Methods: A previously validated two-part nutrition knowledge questionnaire (NKQ) was administered to 101 (37 male and 64 female) non-residential regional Academy of Sport elite youth athletes at an annual training camp. Part 1 of the NKQ presented demographic questions. Part 2 presented 90 sports nutrition knowledge questions in seven knowledge subcategories (1) Nutrients; (2) Dietary reference intakes (DRI); (3) Fluids/ Hydration; (4) Recovery; (5) Weight gain; (6) Weight loss; and (7) Supplements.

Results: The mean NKQ score of all athletes was $43.8 \%$ ( \pm 11.4). No gender differences observed between nutritional knowledge total scores, however female athletes recorded more 'correct' responses than males $(p=0.02)$ in the Nutrients subcategory. Majority of athletes had difficulty identifying correct DRI with this subcategory featuring the lowest percentage of 'correct' to 'incorrect' responses (27.1\% $\pm 2.3 ; p=0.02)$. Supplements subcategory displayed much uncertainty with significantly more 'unsure' than 'incorrect' responses $(42.4 \% \pm 20.3 ; p<0.05)$.

Conclusions: In agreement with previous research, results of the current study indicate that elite youth athletes lack fundamental nutritional knowledge, specifically related to DRI and supplementation. These data provide further support of current recommendations that Academy of Sport youth athletes may benefit from integrated nutrition education conducted by qualified nutrition professionals.
\end{abstract}

Keywords: Nutrition knowledge, Supplements, Youth athletes

\section{Background}

Adolescence is defined by the World Health Organization [1] as a period of significant growth and maturation occurring following childhood and prior to adulthood, with adolescents considered as those between the ages of 10 to 19. It is well established that this period of significant

\footnotetext{
* Correspondence: stephen.bird@usq.edu.au

${ }^{1}$ School of Health and Wellbeing (Sport and Exercise Science), University of Southern Queensland, Ipswich, QLD, Australia

${ }^{2}$ School of Exercise Science, Sport and Health, Charles Sturt University, Bathurst, NSW, Australia

Full list of author information is available at the end of the article
}

growth and physical development can be negatively affected by malnutrition $[2,3]$, as such proper nutrition is of significant importance especially in the competitive adolescent athlete with the added demands of training and competition $[4,5]$. In recent times there has been a rise in youth sports participation [6], however youth athletes may be increasingly pressured to excel in their sport, whether through parents, sporting coaches or intrinsic pressures imposed by the athlete $[7,8]$. In an attempt to gain a competitive edge and improve performance many youth athletes turn to nutritional supplements [9-12]. However, research indicates that youth athletes possess limited

(c) The Author(s). 2020 Open Access This article is licensed under a Creative Commons Attribution 4.0 International License, which permits use, sharing, adaptation, distribution and reproduction in any medium or format, as long as you give appropriate credit to the original author(s) and the source, provide a link to the Creative Commons licence, and indicate if changes were made. The images or other third party material in this article are included in the article's Creative Commons licence, unless indicated otherwise in a credit line to the material. If material is not included in the article's Creative Commons licence and your intended use is not permitted by statutory regulation or exceeds the permitted use, you will need to obtain permission directly from the copyright holder. To view a copy of this licence, visit http://creativecommons.org/licenses/by/4.0/ The Creative Commons Public Domain Dedication waiver (http://creativecommons.org/publicdomain/zero/1.0/) applies to the data made available in this article, unless otherwise stated in a credit line to the data. 
nutritional knowledge [13, 14], with much of their nutritional information obtained via illegitimate sources such as the coach, teacher, other athletes, internet, and social media [15]. Potentially, this may represent a miscommunication from non-qualified individuals providing nutritional advice to athletes that leads to nutritional principles being misunderstood and/or incorrectly applied [16].

Research suggests that collegiate athletes with greater understanding of sound nutritional principles are more likely to apply this knowledge and display positive nutritional behaviors [17]. This is an extremely important consideration, especially for athletes competing in weight-restricted or aesthetic sports wherein youth athletes may feel pressured to restrict caloric intake [18, 19]. Unknowingly, not only may this compromise the athlete's physical development, such nutritional habits may predispose psychological behaviors towards disordered eating traits. Smith-Rockwell et al. [20] revealed that in Division I collegiate coaches/trainers 35\% reported at least one perceived eating disorder case per year, while $10 \%$ reported more than three cases per year. Although many coaches/trainers referred athletes with eating disorder symptoms to physicians, almost one third dealt with these cases themselves. Interestingly, only $30 \%$ of collegiate athletes had access to a sports dietitian, and the same percentage reported utilizing dietitians for nutritional advice [20]. Collectively, this would suggest that reliable sources of nutrition information and education, as well as appropriate nutrition services including counseling are required for collegiate athletes.

Within elite sporting environments there appears to be an increasing trend of coaches and athletic trainers providing nutritional advice [20-22], and this seems to be common practice especially for strength and conditioning coaches [20,23]. A survey of elite rugby union coaches [16] reported that despite responding correctly to only $55 \%$ of all questions on the Nutrition Knowledge Questionnaire (NKQ) [24], 83\% provided nutritional advice to their athletes. Studies assessing coach/athlete nutritional knowledge reported a $67 \%$ correct response rate [20]. Further research solely in athletic populations (age range: $18-37$ yrs) using the same or modified iterations of the NKQ, found nutritional knowledge in elite Australian rules footballers (61\%) [25], professional (54\%) and semi-professional soccer players (56\%) [26], is well below the adequate sports nutrition knowledge overall score of $75 \%$ as proposed by Torres-McGehee et al. [23] This would suggest that both athletes and coaches lack sports nutrition knowledge. Although concerning, the apparent lack of nutritional services available to athletes may be responsible, in part, for necessitating this trend.

While nutritional knowledge and source of nutritional information has been extensively reported in collegiate athletes and coaches/trainers $[9,20,25-30]$, to date, there are no published data on youth athletes from Regional Academy of Sport programs. Recently, Spronk et al. [14] reported that a substantial proportion of what were predominantly youth athletes (16-18 yrs) failed to meet basic dietary recommendations, especially dairy intake. Therefore, it is unclear whether youth athletes have an appropriate level of general nutrition knowledge and understanding of nutrition principles, as much of the literature has focused upon collegiate and semi- or professional athletes [13, 16, 20, 25-28]. Given the potential for a lack of exposure to high quality nutrition-related education, nutrition counselling, and qualified sports nutrition professionals youth athletes may be ill-equipped to make accurate decisions regarding their nutritional requirements, and this in turn may negatively impact their health status, physiological development and/or sports performance.

The purpose of the current study was to examine and describe general nutrition knowledge and nutritionrelated practices of youth athletes from a non-residential Regional Academy of Sport in NSW Australia. Specifically, this study shall quantify nutritional knowledge in youth athletes across a range of academy sports, as well as identifying athletes' primary sources of nutritional information. It was hypothesised that regional youth academy athletes would display limited nutrition knowledge, and this would be related to their primary source of nutritional information.

\section{Methods \\ Participants}

A total of 101 elite youth athletes (37 males, 64 females; state and national competition level; $15.3 \pm 1.4$ years) who were scholarship holders from a non-residential regional Academy of Sport (Western Region Academy of Sport, WRAS) in Australia were invited to participate in this study. Athletes were representative of eight WRAS sports (Netball, Officiating, Basketball, Softball, Hockey, Tennis, Lawn bowls, and Triathlon). Descriptive data is presented in Table $1(n=101)$. After a full explanation of all procedures and possible risks of the investigation, written informed consent was obtained (for participants $<18$ years, a legal guardian also provided written consent). All experimentation was approved by the Charles Sturt University Ethics in Human Research Committee.

\section{Nutrition knowledge questionnaire (NKQ)}

Nutritional knowledge was measured using a previously validated Nutrition Knowledge Questionnaire (NKQ) $[16,24]$. Consultation with an expert panel consisting of a Registered Nutritionist; Sports Dietitian; two Academy Head Coaches; and an Academy Strength and Conditioning coach, was held. Each question was read out loud by the lead researcher and critiqued by the expert 
Table 1 Participant characteristics

\begin{tabular}{|c|c|}
\hline Variable & $\begin{array}{l}\text { Youth Athletes } \\
(\boldsymbol{n}=101)\end{array}$ \\
\hline Age (yrs) & $15.3 \pm 1.4 \mathrm{yrs}$ \\
\hline \multicolumn{2}{|l|}{ Gender } \\
\hline Male & 37 \\
\hline Female & 64 \\
\hline \multicolumn{2}{|l|}{ High School Level } \\
\hline Year 7 (13 yrs) & 11 \\
\hline Year 8 (14 yrs) & 19 \\
\hline Year 9 (15 yrs) & 25 \\
\hline Year 10 (16yrs) & 21 \\
\hline Year 11 (17yrs) & 21 \\
\hline Year 12 (18yrs) & 4 \\
\hline \multicolumn{2}{|c|}{ Years competing at this level } \\
\hline$<1 \mathrm{yr}$ & 26 \\
\hline $2-4 \mathrm{yrs}$ & 63 \\
\hline $5-7$ yrs & 10 \\
\hline $8+\mathrm{yrs}$ & 2 \\
\hline \multicolumn{2}{|c|}{ Training hours per week } \\
\hline $4-6 h$ & 40 \\
\hline $7-10 \mathrm{~h}$ & 42 \\
\hline $11-14 h$ & 15 \\
\hline $15+$ hrs & 4 \\
\hline
\end{tabular}

panel in a group discussion for comprehension, relevance and accuracy. If required, the wording was modified slightly to engage the target demographic of this survey (i.e., high school student-athletes; male and female; aged 13 to 18 years). The NKQ consisted of two distinct sections; Section 1 presented demographic questions including age, level of competition, training load expressed as hours of training per week, education level and primary source of nutrition information. Section 2 presented 90 sports nutrition knowledge questions in seven subcategories.

1. Nutrients

2. Dietary reference intake (DRI)

3. Fluids/Hydration

4. Recovery

5. Weight gain

6. Weight loss

7. Supplements

Each question had a potential answer of "yes", "no" or "unsure", with a correct response was coded as +1 whilst incorrect or unsure responses were coded as 0 . The rationale for the inclusion of an unsure response is to deter subjects from guessing responses in the NKQ as suggested by Zinn et al. [16] All athletes attended a nutrition research session in the same room at the annual training camp. The NKQ was distributed to athletes in hard copy format with the lead researcher providing specific instructions on how to complete the NKQ, which took taking approximately $45 \mathrm{~min}$ to complete under the supervision of the researchers.

\section{Statistical analysis}

Descriptive statistics were used to analyze the demographic information. Nutrition knowledge sub-scores for each section and an overall nutrition knowledge total score was calculated. Percentage of 'correct', 'unsure', and 'incorrect' responses to each individual item was analyzed. Independent $\mathrm{t}$-tests were used to show mean correct, incorrect, and unsure score differences between the two groups (male and female athletes). All data were coded, entered numerically and analyzed using SPSS version 21.0 (SPSS Inc., Chicago, IL, USA, 2012) with significance set at $p<.05$. Data are presented as percentages, means, and standard deviations.

\section{Results}

\section{Nutritional knowledge}

Figure 1 presents the mean percentage of 'correct', 'incorrect', and 'unsure' total scores obtained by youth athletes on the NKQ. The mean overall score was $43.8 \pm$ $11.4 \%$ (pooled data) with significantly more $(p<0.01)$ 'correct' responses compared to 'unsure' responses. No significant gender differences were observed between nutritional knowledge total scores, however subcategory differences were evident.

\section{Subcategory knowledge}

Figure 2 displays the subcategory knowledge mean percentage of 'correct', 'incorrect', and 'unsure' total scores obtained by youth athletes on the NKQ.

\section{Nutrients}

Subjects correctly answered $51 \%$ of questions within this section. There was a greater number of 'correct' responses in this subcategory compared with 'unsure' $(p<$ 0.01 ). Interestingly, $72 \%$ of subjects incorrectly stated 'avocados were low in fat', while $51 \%$ incorrectly identified 'chicken as a high carbohydrate food'. An independent t-test showed that females obtained more 'correct' responses than males $(p=0.02)$.

\section{Dietary reference intakes}

This subcategory was the most poorly answered of all the subcategories and featured the lowest percentage of 'correct' to 'incorrect' responses ( $27 \%$ vs. $43 \%$, respectively; $\mathrm{p}=0.02$ ). Notably, 37 and $38 \%$ of athletes 


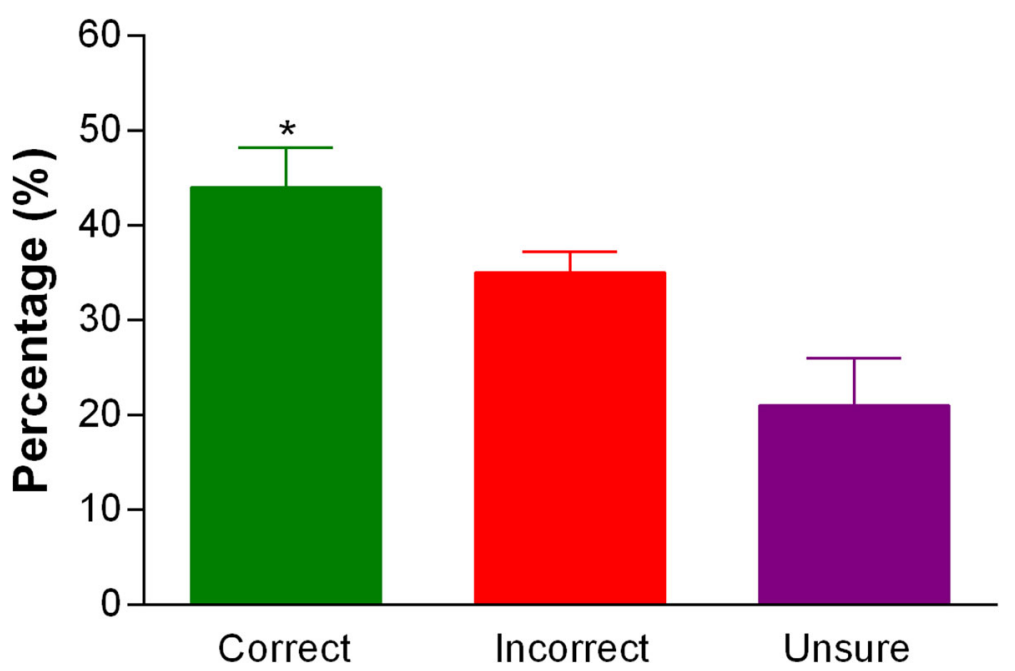

Fig. 1 Mean percentage score of correct, incorrect and unsure total scores obtained by subjects on the nutritional knowledge questionnaire. * Significantly greater than 'unsure' and 'incorrect'

responded 'unsure' and 'incorrect', respectively, to the protein recommendations for youth athletes. Additionally, carbohydrate recommendations were incorrectly identified by $45 \%$ of athletes.

\section{Fluids/hydration}

Less than half $(46 \%)$ of the fluid/hydration questions were answered correctly. Regarding fluid ingestion, $72 \%$ of respondents were unable to correctly identify the fluid requirements for an intense two-hour training session and only $9 \%$ correctly identified the carbohydrate content range of a standard sports drink.

\section{Recovery}

Only half (54\%) of the recovery questions were answered correctly. Regarding carbohydrates and recovery, not only was the definition of Glycemic Index a source of confusion with $45 \%$ responding 'unsure' but $64 \%$ of athletes incorrectly identified green salad as containing more carbohydrates than soft drink.

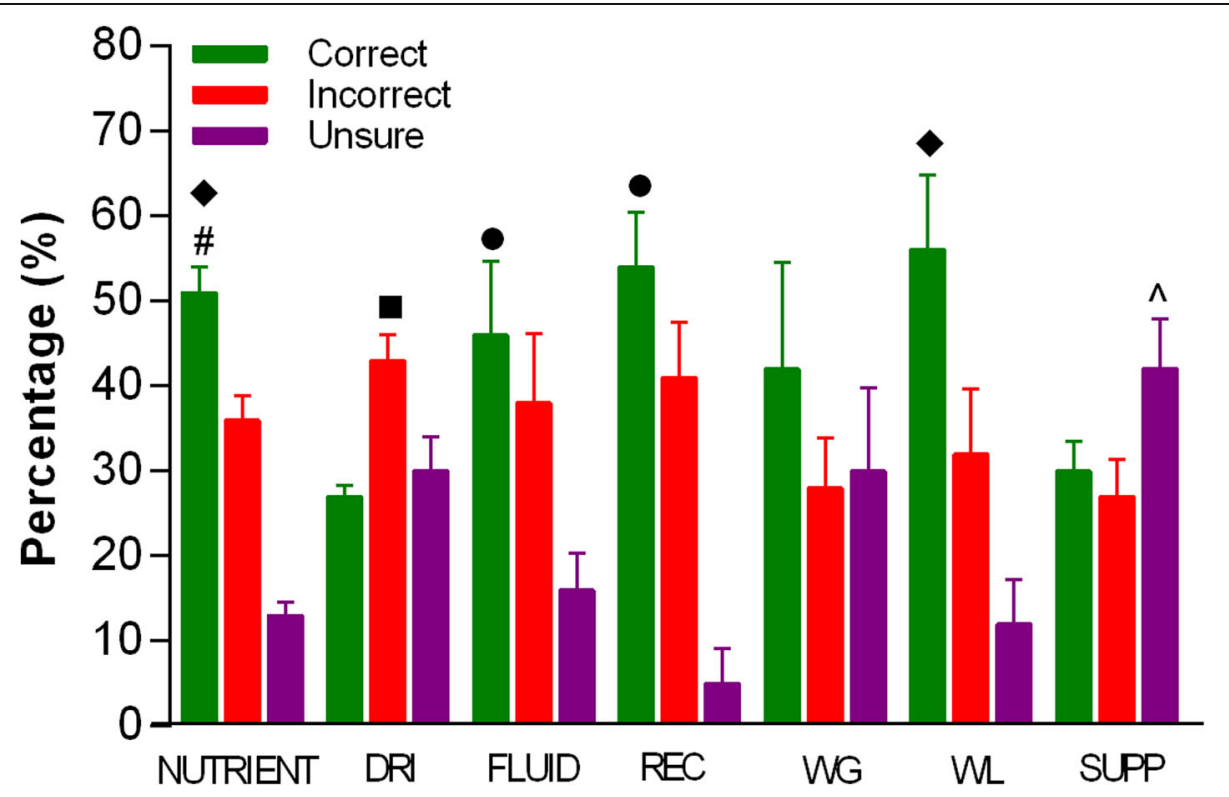

Fig. 2 Subcategory knowledge mean percentage score of correct, incorrect and unsure totals scores across the seven subcategories. Significantly greater than 'incorrect' and 'unsure'; - Significantly greater than 'correct'; • Significantly greater than 'unsure'; ^ Significantly greater than 'incorrect'; \# Significantly more 'correct' responses for females than males. Abbreviations: DRI $=$ Dietary reference intakes, REC $=$ Recovery, WG $=W e i g h t$ gain, $W L=$ Weight loss, SUPP = Supplements 


\section{Weight gain and weight loss}

A substantial variation in mean correct percentage scores within this subcategory was evident with 'correct' responses ranging from 3 to $78 \%$. More than half of the athletes $(54 \%)$ reported that consuming protein powder is essential to increase muscle mass, while $67 \%$ were 'unsure' what type of protein was most suitable for gaining muscle mass. The weight loss section had significantly more $(56 \% ; p<0.05)$ 'correct' responses compared to 'incorrect' and 'unsure'.

\section{Supplements}

Collectively, the responses for this subcategory displayed much uncertainty with significantly more 'unsure' responses to these questions than 'incorrect' responses (42\%; $\mathrm{p}<0.05$ ). One third of youth athletes reported protein supplement use over the previous 12 months (Fig. 3); however, athletes lacked knowledge as to why you would take this supplement with $45 \%$ of athletes responding 'unsure'. Further questions pertaining to creatine supplementation and hydroxy-methyl butyrate (HMB) resulted in similar 'unsure' responses of 63 and 70\%, respectively. Overall, there was a greater number of 'unsure' responses in this subcategory compared with any other subcategory $(p=0.02)$.

\section{Source of nutritional information}

Figure 4 presents the reported sources of nutritional information of youth athletes. Notably, $45 \%$ of athletes reported that the coach was the primary source of nutrition information, followed by books/magazines (27\%). Dietitians were only reported for $16 \%$ of athletes with minor sources of nutritional information including the internet and other athletes (10\%).

\section{Discussion}

Results from the current study indicate that youth athletes lack nutritional knowledge in multiple areas, with only two subcategories recording mean 'correct' responses above 50\%. Athletes' nutritional knowledge were particularly lacking pertaining to the areas of nutrient recommendations and supplementation, indicating the need for further nutrition education. This may predispose youth athletes to make inadequate nutrition and/or supplementation choices based on misconceptions and/ or misinformation that may negatively impact growth, physical development and performance [4].

The results of current study further support recommendations for nutrition education programs for both youth athletes [31] and coaches [23], as Little et al. [31] has shown that as little as five nutrition education sessions can be effective in improving nutrition and supplement knowledge in youth athletes from low-income communities. This may be reflective of the youth athletes in the current study, with many of the geographical locations (inland regional and rural towns) recognized as low socioeconomic communities.

Our study revealed that the coach represented the main source of nutritional information for athletes (45\%), whilst dietitians represented only $16 \%$. Previous research has demonstrated that professional coaches recorded mean nutritional knowledge scores ranging from 48 to $67 \%[16,20]$, as such it may be fair to assume that coaches of youth athletes may likely have comparable or

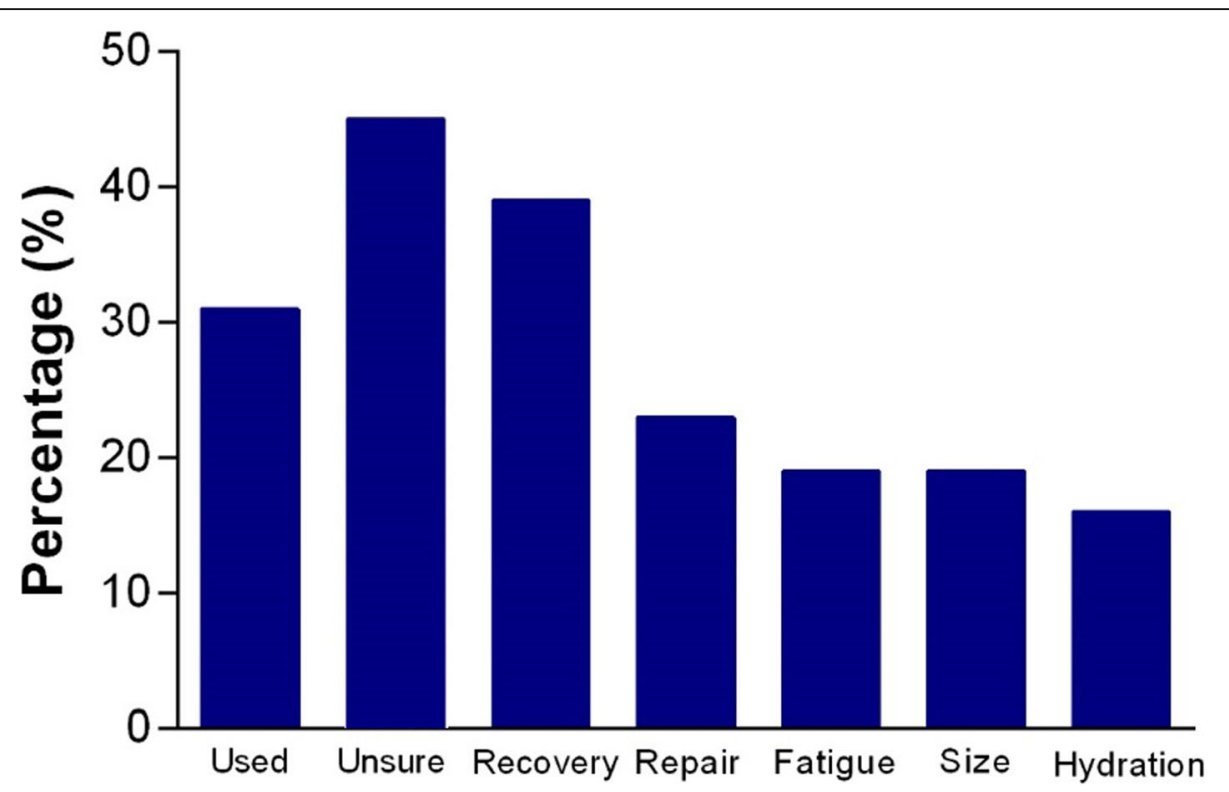

Fig. 3 Protein supplementation. Percentage of youth athletes using a protein supplement in the last 12 months and the reason provided for usage 


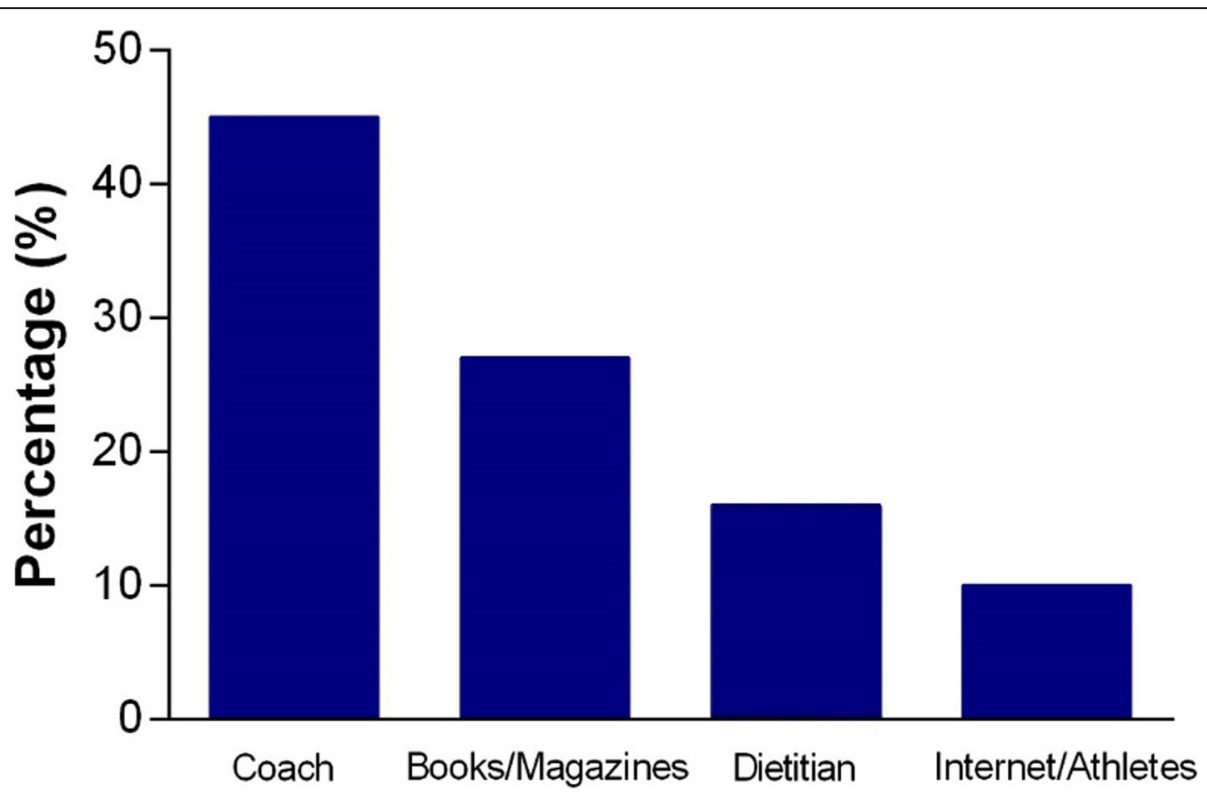

Fig. 4 Source of nutrition information. Mean percentage score of where youth athletes source nutrition information

lower levels of nutrition knowledge. However, this was not measured in the current study. The low incidence of dietitians being sourced to provide nutritional advice is of concern, however these data are similar to other reports [32]. Despite youth athletes in the current study being classified as 'elite', with competition level ranging from state, national and international, the rural location of the academy and the added expense of dietetic consultations likely presents barriers for athletes from regional and rural areas to source expert services. SmithRockwell et al. [20] reported that strength and conditioning coaches/trainers with access to a dietitian made full use of these services. Therefore, increased accessibility may result in greater usage of qualified sports nutrition professionals as the primary source of nutrition information and education. With greater access to nutrition support services, one could expect that athletes would exhibit higher nutritional knowledge [14, 25, 26].

Conversely, Burns and colleagues [32] found that even with access to an available dietitian, collegiate athletes preferred to source athletic trainers (39\%), and strength and conditioning coaches (23\%) for nutrition information more than dietitians (14\%). This may suggest that even with increased availability of dietitians, integration and collaboration between qualified nutrition professionals, strength and conditioning coaches, and athletic trainers may be required to refer athletes to the dietician and thereby provide greater opportunities for athletes to interact with nutrition support services. Such an integrated approach is an important consideration as athletic training staff are noted to be key influencers on nutrition behavior and decisions, particularly in younger athletes $[33,34]$.

In the current study, the athletes' knowledge of DRI was particularly lacking with majority of respondents incorrectly identifying recommended DRI values for carbohydrate, fat and protein, with mean correct scores of 26,26 and $30 \%$ respectively. The high percentage of 'incorrect' and 'unsure' responses clearly demonstrates that regional youth athletes display a lack of DRI nutrition knowledge. Interestingly, athletes displayed higher knowledge in the subcategory of weight loss compared to weight gain, with more correct (59\% vs. $42 \%)$ and fewer unsure $(28 \%$ vs. $32 \%)$ responses, respectively. This contrast may be reflective of increased exposure to health promotion campaigns and social media targeted at reducing obesity in the Australian population, as an inundation of information regarding weight loss is highlighted throughout all media outlets. This may lead to youth athletes questioning whether it is healthy and/ or acceptable to increase their energy intake despite well-established guidelines that youth athletes require greater caloric intakes to support growth, development and physical activity $[3,4]$.

The supplementation subcategory displayed the second least 'correct' responses across all categories with greatest number of 'unsure' responses. This further supports the works of Little et al. [31] who highlight that youth athletes have poor understanding of concepts related to nutrition supplements. Specifically, related to protein supplementation, Petróczi and colleagues [35] reported $21-44 \%$ of young elite UK athletes (12-21 yrs) 
supplemented with whey protein. This is consistent with the current investigation wherein $31 \%$ of youth athletes reported protein supplement use. It should be noted that while there was a high "unsure" response rate to creatine and $\mathrm{HMB}$ (63 and 70\%, respectively), these are quite technical terms and potentially unknown to youth athletes. More than reflecting their knowledge and therefore the health hazard it might also convey the athletes are unfamiliar with these kinds of supplements. Collectively, these data indicate that not only do youth athletes use dietary supplements, but perhaps more importantly, they lack knowledge pertaining to the efficacy and risks of protein supplements. Self-managed supplementation strategies employed by youth athletes may partially explain the observed lack of congruence between reasons and supplement used [35].

As with all research there are potential limitations that should be acknowledged. Firstly, difference in the male and female sample size are apparent and while significant difference observed in the nutrition category may be due to the unequal sample sizes the statistical analysis and framework used in the manuscript is consistent with publications in the area. Secondly, the NKQ used was based on a questionnaire previously determined to have construct validity [24], however some questions underwent minor word changes to account for the specific population studied, that of regional academy youth athletes. While the overall questions remained the same, some questions were rephrased to be in the second person tense. As highlighted by Abbey and colleagues [36], acknowledging that no questionnaire is completely robust, the chosen NKQ was deemed the easiest to assess nutrition knowledge in regional academy youth athletes.

\section{Conclusion}

In agreement with previous research [13, 14], it was evident that non-residential Academy of Sport youth athletes from regional and rural areas displayed several misconceptions regarding general nutrition. Specifically, DRI and supplementation have been identified as key areas requiring targeted education. Secondly, with the tendency for athletes to source nutrition information from coaches/ trainers, general nutrition education for coaching staff is highly recommended as this may offer a flow-on effect for enhancing youth athlete nutrition knowledge via coaches' reinforcement of sound nutrition principles $[16,20,21$, 37]. This is an important consideration given that few youth athletes seek nutrition information from appropriately qualified nutrition professional, especially in regional Academy of Sport programs that may lack such resources. A better understanding of nutrition knowledge in youth athletes will allow nutrition education interventions to target areas in need of improvement. These data provide further support to current recommendations that athletes
[31] and coaches [16, 23] would benefit from nutrition education integrated into Academy of Sport programs conducted by qualified nutrition educators, especially for young male athletes.

\section{Abbreviations \\ DRI: Dietary reference intakes; HMB: hydroxy-methyl butyrate; NKQ: Nutrition knowledge questionnaire; WRAS: Western Region Academy of Sport}

\section{Acknowledgments}

The authors would like to thank the athletes and coaches from the Western Region Academy of Sport.

\section{Consent to publish}

Not applicable.

\section{Authors' contributions}

SPB conceived and designed the study, coordinated the study and statistical analysis, contributed to and reviewed the draft manuscript. BDR drafted the manuscript and participated in the statistical analysis. Both authors read and approved the final manuscript. The authors have read and approved the final version of the manuscript and agree with the order of presentation of the authors.

Funding

No funding was received for the project.

Availability of data and materials

Availability of dataset can be given upon reasonable request to the first and/ or corresponding author.

\section{Ethics approval and consent to participate}

The study was approved by the Charles Sturt University Ethics in Human Research Committee, Approval/Protocol Number: 2007/057. All participants provided written informed consent to participate in the study with written informed consent provided by Parent/Guardian for participants under the age of 18

\section{Competing interests}

The authors declare that they have no competing interests.

\section{Author details}

${ }^{1}$ School of Health and Wellbeing (Sport and Exercise Science), University of Southern Queensland, Ipswich, QLD, Australia. ${ }^{2}$ School of Exercise Science, Sport and Health, Charles Sturt University, Bathurst, NSW, Australia. ${ }^{3}$ School of Exercise and Nutrition Sciences, Faculty of Health, Deakin University, Melbourne, VIC, Australia.

Received: 3 November 2019 Accepted: 1 July 2020

Published online: 18 August 2020

\section{References}

1. WHO. Child and adolescent health and development. Progress report 20062007. Geneva: World Health Organization; 2008.

2. Kulin HE, Bwibo N, Mutie D, Santner SJ. The effect of chronic childhood malnutrition on pubertal growth and development. Am J Clin Nutr. 1982; 36(3):527-36.

3. Steen SN. Timely statement of the American dietetic association: nutrition guidance for adolescent athletes in organized sports. J Am Diet Assoc. 1996; 96(6):611-2.

4. Desbrow B, McCormack J, Burke LM, et al. Sports dietitians Australia position statement: sports nutrition for the adolescent athlete. Int J Sport Nutr Exerc Metab. 2014:24(5):570-84

5. Steen SN. Nutrition for young athletes. Special considerations. Sports Med. 1994:17(3):152-62.

6. Fraser-Thomas JL, Côté J, Deakin J. Youth sport programs: an avenue to foster positive youth development. Phys Educ Sport Pedagog. 2005;10(1): $19-40$. 
7. Flett GL, Hewitt PL. "The perils of perfectionism in sports" revisited: toward a broader understanding of the pressure to be perfect and its impact on athletes and dancers. Int J Sport Psychol. 2014;45(4):395-407.

8. Leff SS, Hoyle RH. Young athletes' perceptions of parental support and pressure. J Youth Adolesc. 1995;24(2):187-203.

9. Froiland K, Koszewski W, Hingst J, Kopecky L. Nutritional supplement use among college athletes and their sources of information. Int J Sport Nutr Exerc Metab. 2004;14(1):104-20.

10. McDowall JA. Supplement use by young athletes. J Sport Sci Med. 2007;6(3): 337-42.

11. Sousa M, Fernandes MJ, Carvalho P, Soares J, Moreira P, Teixeira VH Nutritional supplements use in high-performance athletes is related with lower nutritional inadequacy from food. J Sport Health Sci. 2016;5(3):368-74.

12. Cotunga N, Vickery CE, McBee S. Sports nutrition for young athletes. J Sch Nurs. 2005:21(6):323-8

13. Spendlove JK, Heaney SE, Gifford JA, Prvan T, Denyer GS, O'Connor HT Evaluation of general nutrition knowledge in elite Australian athletes. $\mathrm{Br}$ J Nutr. 2012;107(12):1871-80

14. Spronk I, Heaney SE, Prvan T, O'Connor HT. Relationship between general nutrition knowledge and dietary quality in elite athletes. Int J Sport Nutr Exerc Metab. 2015:25(3):243-51.

15. Nowak M, Speare R. Gender differences in food-related concerns, beliefs and behaviours of North Queensland adolescents. J Paediatr Child Health. 1996;32(5):424-7.

16. Zinn C, Schofield G, Wall C. Evaluation of sports nutrition knowledge of New Zealand premier club rugby coaches. Int J Sport Nutr Exerc Metab. 2006;16(2):214-25

17. Jacobson BH, Sobonya C, Ransone J. Nutrition practices and knowledge of college varsity athletes: a follow-up. J Strength Cond Res. 2001;15(1):63-8.

18. Martinsen M, Bratland-Sanda S, Eriksson AK, Sundgot-Borgen J. Dieting to win or to be thin? A study of dieting and disordered eating among adolescent elite athletes and non-athlete controls. Br J Sport Med. 2010; 44(1):70-6.

19. Petrie HJ, Stover EA, Horswill CA. Nutritional concerns for the child and adolescent competitor. Nutrition. 2004;20(7-8):620-31.

20. Smith-Rockwell M, Nickols-Richardson SM, Thye FW. Nutrition knowledge, opinions, and practices of coaches and athletic trainers at a division 1 university. Int J Sport Nutr Exerc Metab. 2001;11(2):174-85.

21. Juzwiak CR, Ancona-Lopez F. Evaluation of nutrition knowledge and dietary recommendations by coaches of adolescent Brazilian athletes. Int J Sport Nutr Exerc Metab. 2004;14(2):222-35.

22. Shoaf LR, McClellan PD, Birskovich KA. Nutrition knowledge, interests, and information sources of male athletes. J Nutr Edu. 1986;18(6):243-5

23. Torres-McGehee TM, Pritchett KL, Zippel D, Minton DM, Cellamare A, Sibilia M. Sports nutrition knowledge among collegiate athletes, coaches, athletic trainers, and strength and conditioning specialists. J Athl Train. 2012;47(2): 205-11.

24. Zinn C, Schofield G, Wall C. Development of a psychometrically valid and reliable sports nutrition knowledge questionnaire. J Sci Med Sport. 2005;8(3): 346-51

25. Devlin BL, Belski R. Exploring general and sports nutrition and food knowledge in elite male australian athletes. Int J Sport Nutr Exerc Metab. 2015;25(3):225-32

26. Andrews MC, Itsiopoulos C. Room for improvement in nutrition knowledge and dietary intake of male football (soccer) players in Australia. Int J Sport Nutr Exerc Metab. 2016;26(1):55-64.

27. Corley G, Demarest-Litchford M, Bazzarre TL. Nutrition knowledge and dietary practices of college coaches. J Am Diet Assoc. 1990;90(5):705-9.

28. Dunn D, Turner LW, Denny G. Nutrition knowledge and attitudes of college athletes. Sport J. 2007;10:4

29. Heaney S, O'Connor H, Michael S, Gifford J, Naughton G. Nutrition knowledge in athletes: a systematic review. Int J Sport Nutr Exerc Metab. 2011;21(3):248-61.

30. Jacobson BH, Aldana SG. Current nutrition practice and knowledge of varsity athletes. J Strength Cond Res. 1992;6(4):232-8

31. Little JC, Perry DR, Volpe SL. Effect of nutrition supplement education on nutrition supplement knowledge among high school students from a lowincome community. J Community Health. 2002;27(6):433-50.

32. Burns RD, Schiller MR, Merrick MA, Wolf KN. Intercollegiate student athlete use of nutritional supplements and the role of athletic trainers and dietitians in nutrition counseling. J Am Diet Assoc. 2004;104(2):246-9.
33. Graves $\mathrm{KL}$, Farthing MC, Smith SA, Turchi JM. Nutrition training, attitudes, knowledge, recommendations, responsibility, and resource utilization of high school coaches and trainers. J Am Diet Assoc. 1991;91(3):321-4.

34. Hackman RM, Katra JE, Geertsen SM. The athletic trainer's role in modifying nutritional behaviors of adolescent athletes: putting theory into practice. J Athl Train. 1992;27(3):262-7.

35. Petróczi A, Naughton DP, Pearce G, Bailey R, Bloodworth A, McNamee M. Nutritional supplement use by elite young UK athletes: fallacies of advice regarding efficacy. J Int Soc Sports Nutr. 2008;5(1):22.

36. Abbey EL, Wright CJ, Kirkpatrick CM. Nutrition practices and knowledge among NCAA division III football players. J Int Soc Sports Nutr. 2017;14(1):13.

37. Baer JT, Dean DJ, Lambrinides T. How high school football coaches recommend their players gain lean body mass. J Strength Cond Res. 1994; $8(2): 72-5$

\section{Publisher's Note}

Springer Nature remains neutral with regard to jurisdictional claims in published maps and institutional affiliations.
Ready to submit your research? Choose BMC and benefit from:

- fast, convenient online submission

- thorough peer review by experienced researchers in your field

- rapid publication on acceptance

- support for research data, including large and complex data types

- gold Open Access which fosters wider collaboration and increased citations

- maximum visibility for your research: over $100 \mathrm{M}$ website views per year

At BMC, research is always in progress.

Learn more biomedcentral.com/submissions 